\title{
The Role(s) of Image for Young Bilinguals Reading Multimodal Informational Texts
}

\author{
LINDSEY MOSES \\ Mary Lou Fulton Teachers College, Arizona State University
}

\begin{abstract}
The purpose of this study was to examine how young bilinguals construct meaning with multimodal informational texts. The most frequently used literacy practice to support the meaning construction involved viewing an image. The function of image played four distinct, but important roles: image as access to meaning and content; image as prompt for discussion; image as a catalyst to seek access to written language; image as a multimodal complement to written language. The roles were examined using a case study approach that drew on multiple levels of analysis in order to describe content knowledge and language development among first-grade bilinguals over an academic year.
\end{abstract}

Informational texts and text complexity are at the forefront of current educational conversations as educators continue to focus on preparing college-ready students in increasingly demanding educational and workforce settings. In addition to typical considerations for educating students, teachers must also take into consideration their culturally and linguistically diverse populations. As the amount of informational texts and higher-order thinking skills are emphasized, new research on language and literacy development is warranted, particularly with young bilinguals. In this study, I examine how bilinguals engage with the visual images offered in print-based multimodal informational texts as a way to gain a deeper understanding of possible roles the mode of image in informational text might play in meaning construction and language development for young bilinguals in an inquiry-based classroom.

In the United States, the context of this research, a great deal of research and instruction in the primary grades is focused on phonics, decoding and literal level skills as some scholars believe children are "learning to read" before moving into "reading to learn" in upper elementary grades (Chall, 1983). However, multiple researchers call for an in-depth examination of how young children are engaging with multimodal texts (e.g. Hassett \& Schieble, 2007; Serafini, 2012; 2014). Multimodal texts are broadly defined as texts with more than one mode (e.g., combinations of written language, photography, illustrations, sculpture, etc.). As such, most picturebooks found in elementary classrooms are multimodal because readers of picturebooks are constantly engaging with multiple modes (i.e., illustration, written language, etc.). The print-based multimodal informational texts in this study included the modes of illustrations, written language, photography, and diagrams. Kress (2003) argues that language can no longer be considered the sole or dominant means for representing and communicating ideas and concepts, and he points out that language in isolation fails to provide access to the full meaning potential in multimodal texts. 
It is essential to investigate how young children are transacting with multimodal informational texts in order to provide more effective classroom instruction. A deeper understanding of students' interactions with multimodal texts requires research on the various roles visual images, written language and design features play in these interactions. In this study, young bilinguals' engagement with informational texts are examined through an ethnographic approach drawing on multiple levels of analysis in order to describe the content knowledge and language development among first-grade bilinguals over an academic year. The following research questions guided this study:

1. How do young bilinguals construct meaning with print-based multimodal informational texts?

2. How do these transactions with texts support content knowledge and language development?

I first present a review of the literature related to the academic performance of young bilinguals and the use of informational and multimodal texts in classroom settings. Following this review, I provide background on the methodology used in the study, including the research design, setting, and data collection and analysis. I then present the findings of the study categorized into the four roles image plays in supporting the interactions and construction of meaning with multimodal texts by young bilinguals. I conclude the article with discussion considerations, limitations, possibilities for future research, and several implications for classroom instruction.

\section{Literature Review}

Early childhood experts have long touted the importance of images and additional modes for meaning making (Clay, 1982; Clay, 2000; Dyson, 2013; Gallas, 1993). Clay's seminal work on "Concepts About Print" reveals that young children rely on the image/picture to carry the message because they are not yet able to read the print. She also explains that as their understanding of letters/sounds/words increases, then they turn to the text to contain the message instead of the picture. While essential to our understanding of literacy development for young readers, Clay's research (1982) is conducted with and focused primarily on young monolingual speakers in the early emergent and emergent stages of literacy and was completed prior to the more recent and extensive research in the area of visual modality and picturebooks (Painter, Martin, \& Unsworth, 2013; Serafini, 2010, etc.). This study addresses the need for research on bilinguals who already possess many "Concepts About Print" and are learning a new language. By better understanding the roles of image in meaning-making with young bilinguals, teachers can provide instruction to scaffold engagement with language and content through various uses of image.

\section{Instruction for English Learners}

As the classrooms in the United States continue to reflect a growing diversity in the country's demographic makeup, there is a need for additional research examining what constitutes effective instruction for young bilinguals. The number of children entering school who are fortunate enough to speak an additional language at home is 
increasing at a much more rapid rate than the overall school-aged population (Office of English Language Acquisition, Language Enhancement and Academic Achievement for Limited English Proficient Students, 2010). However, students acquiring English as an additional language continue to be outperformed on assessments in English by native speakers in the United States (National Assessment of Educational Progress, 2009). From an international perspective, PISA data reports that English language learners' performance in countries such as Canada tends to be better than the US (Cummins, Mirza, \& Stille, 2012), but academic performance of English language learners is still significantly below that of the native English speakers (Kilbride \& D'Arcangelo, 2002). Reading comprehension struggles, as documented by assessments in English, are prevalent for bilinguals (NCES, 2011) possibly because of limited background knowledge and underdeveloped vocabulary in their second language, English (Bradley \& Bryant, 1983; Hulme, Muter, Snowling, \& Stevenson, 2004; National Research Council, 1997).

\section{Informational Text in the Classroom}

Interacting with informational texts provides opportunities to draw on young bilinguals' background knowledge about the world around them while simultaneously developing vocabulary. Engagement with this type of text has been documented to motivate young learners and encourage overall literacy development (Caswell \& Duke, 1998). Researchers have reported substantial benefits of increased exposure, access and knowledge about informational texts (Pappas, 1991; Purcell-Gates, Duke, \& Martineau, 2007). However, there continues to be a documented scarcity of informational texts in primary classrooms (Duke, 2000; Jeong, Gaffney, \& Choi, 2010). The lack of exposure and instruction about navigating multimodal informational texts puts young bilinguals at a disadvantage for acquiring content knowledge, advancing language acquisition and engaging in authentic literacy practices.

\section{Multimodal Texts}

The notion of literacy has been expanded to encompass more than the decoding of printed text of written language (Kress, 2010; Narey, 2009; New London Group, 1996;). Multimodal perspectives on literacy development address the roles that visual images, typography, design features play in children's literacy development in addition to written language. Multiple researchers argue that when considering the bimodal form of text found in picturebooks, the visual modality is equally as important as the written language during transactions with readers creating meaning (Anstey \& Bull, 2000; Arizpe \& Styles, 2003; Serafini, 2010; Unsworth \& Wheeler, 2002). It is no longer simply one's ability to decode written language that makes one a proficient reader.

As the societal and educational demands increase for sophisticated meaning construction and the navigation of complex texts, "One must reconceptualize the reader as reader-viewer attending to the visual images, structures and designs of multi-modal texts along with printed text" (Serafini, 2012, p. 152). Various literacy educators conceptualize visual images and design features as separate semiotic systems that work in conjunction and separately from written language to communicate meaning and concepts rather than simply serving as a prompt or stepping stone for the reading of written 
language (Painter, Martin, \& Unsworth, 2013; Sipe, 1998). Because of this, teachers need to support readers' interpretations of visual image as well as the decoding of written language. The greatest challenge, "is that although knowledge about language - for example, about sound/letter relationships, grammar, punctuation and literary technique are part of the toolkit of all literacy educators, relevant knowledge about how images work is less widespread" (Painter, Martin, \& Unsworth, 2013, p. 2). Teachers' understanding of the meanings constructed by visual choices can assist in supporting students' transactions with multimodal texts. In turn, it becomes essential for educators to consider these implications and alter their instructional practices to meet the demands of complex multimodal texts as well as support their diverse classroom settings to expand beyond an exclusive focus on decoding written language. The focus on developing visual and multimodal literacy skills (e.g. Kress \& van Leeuwen, 2006) is particularly crucial to understanding how young bilinguals are constructing meaning with multimodal informational text in the early stages of learning to decode.

Informational texts focusing on science concepts include an array of design features or visual images (Lemke, 1998), and young children are faced with navigating the multimodal nature of these texts. Viewing images in informational picturebooks has been reported to not only enhance meaning making (Guccione, 2011), but also become a cultural tool for bilinguals in order to participate in classroom communities of practice in inquiry settings (Moses, 2013). Viewing images facilitated the possibility for young bilinguals to draw on background knowledge, gain access to content and share their new understandings with peers.

While some researchers report that visual images do not contribute to meaning construction and can actually detract from it (Watkins, Miller, \& Brubaker, 2004), many second language researchers (e.g. Echevarria, Short, \& Vogt, 2008; Herrera, Perez, \& Escamilla, 2010; Yatvin, 2007) contend that images assist in meaning construction and language acquisition by making content comprehensible for bilinguals. Guccione (2011) reported viewing images to be the most frequently used literacy practice by first-grade bilinguals to assist in meaning construction when reading informational text. Mohan's (1986) systematic approach to integrating content objectives and language objectives across the curriculum includes a focus on knowledge structures across curricula. Additionally, he has identified key visuals (images, graphic organizers, graphs, etc.) that lend themselves to each type of knowledge structure. Early (1990) has identified these key visuals as having "at least three major applications: (1) generative- to promote content-related language production, (2) explanatory- to increase content understanding, and (3) evaluative- to assess content of language understanding" (p. 84). This study builds on the work of previous scholars and examines the specific roles of images in informational texts in an inquiry-based classroom. A better understanding of these roles can provide instructional implications for supporting young children in diverse classroom settings.

The body of research on constructing meaning with text and effective instruction for young bilinguals is growing, but "few researchers have examined the ways in which young children engage with informational texts in the context of a classroom" (Maloch \& Zapata, 2012, p. 308), and even fewer have done so with young bilinguals. There remains a need for research that examines aspects of learning beyond the linguistic text-based 
instructional methodologies, specific cognitive strategies and curricular choices. While there is value in using images as scaffolds or bridging functions to enable students to "crack the code" and develop literacy in their second language (Gibbons, 2002), there remains alternative uses and purposes of the mode of image found in informational texts that reach beyond accessing the written language. This study examines how young bilinguals construct meaning with multimodal informational texts, the roles that visual images play, and how these transactions support both knowledge and language development.

\section{Methods}

This study is part of a larger, yearlong educational ethnography with a weighted qualitative approach (Creswell, 2002) that utilized quantitative data, but provided greater weight in the design for the thick, rich description found in qualitative data (Geertz, 1973). I utilized descriptive statistics to identify language and literacy proficiency levels of the bilingual case studies. Additionally, I conducted frequency counts of observed literacy practices used during interactions with multimodal informational texts. While the descriptive statistics provided important background information about the case studies and their most frequent use of literacy practices, my epistemological stance is deeply rooted in social constructionism. This study was grounded in the notion that all knowledge and meaningful reality "is contingent upon human practices being constructed in and out of interaction between human beings and their world, and developed and transmitted within an essentially social context" (Crotty, 1998, p. 42). Because of this, the weighted qualitative component drew on microethnographic (Bloome, Carter, Christian, Otto, \& Shuart-Faris, 2005) and case study methods (Merriam, 1998) to record and document student transactions with texts, classroom practices and discourse. I was a participant observer (Creswell, 2002) in order to enhance the naturalistic inquiry (Guba \& Lincoln, 1981) over the course of an academic year.

\section{Setting and Participants}

Purposeful sampling (Creswell, 2007) was used to select a first-grade classroom with the following characteristics: high percentage of students whose home language was Spanish; a student-centered classroom with an inquiry-approach to learning; a classroom that included daily instruction and transactions with informational texts. The studentcentered classroom included a two-hour literacy block that consisted primarily of students working individually, in partners or small groups on inquiry research projects on topics of their choice. The teacher taught mini-lessons about reading, writing and research strategies approximately twice a week as well as met with small groups and conducted conferences for needs-based instruction. The majority of students' time was spent, reading, writing, viewing and talking with peers and the teacher about research topics of interest. The selected inquiry-based first-grade classroom was located in the western United States. The school population had 75 percent of students who were learning English as a second language. Ninety percent of the students qualified for federally subsidized lunches.

The yearlong study included all students in the first-grade classroom which was composed of both monolingual English speakers and emerging bilinguals. For the 
specific aspect of the study focused on the roles of images for young bilinguals, five bilingual case studies with the widest ranging scores of English proficiency (as documented by the state language proficiency assessment) were selected for this study: Xochitl, Paloma, Angel, Maria, and Julio. Their scores ranged from "Non English Proficient" to "Limited English Proficient". There were no bilinguals whose assessment reflected the score of "Fully English Proficient". At the beginning of the year, the case studies were not yet independently decoding written language at a first grade level, but three of the case studies could identify the names of all of the letters and over half of the sounds.

\section{Data Collection}

I utilized two camcorders and four voice recorders to capture data once a week during the Language Arts period for an entire academic year. The Language Arts period varied daily and included teacher-directed lessons, small group work, and partner or independent reading, writing and research. Each week I produced and catalogued still photography, kept detailed field notes, wrote a researcher reflection journal and collected student artifacts and assessment data.

Ongoing, informal interviews took place with the students during observations and interactions. The informal and open-ended interviews typically involved asking students to talk to me about their thinking, reading, writing and/or interactions with texts. This type interview was selected because it is viewed "as the most helpful for generating data on the children's perspective" (Einarsdottir \& Wagner, 2006, p. 245). I also conducted formal, semi-structured interviews with all the students at the beginning, middle, and end of the school year regarding their perceptions on language and literacy learning, units of inquiry, content knowledge, reflections on their portfolios, and transactions with texts. Questions of validity regarding interviews with young children are prevalent in research literature (Einarsdottir \& Wagner, 2006; Kvale, 1996). Because of this, I used open and semi-structured interviews as one of multiple data sources in order to provide triangulation for constructed themes and analysis.

\section{Data Analysis}

The initial layer of video analysis was completed weekly by creating video recording summaries which documented events and timed location of events approximately every 30 seconds to one minute. I used open coding (Strauss, 1987) to document and discover meaning during the creation of the video running records. Upon completion of the running record summaries and open coding, I began axial coding (Strauss, 1987). I created a code for observed literacy practices related to multiple aspects of examining how young bilinguals constructed meaning with informational texts.

Data were coded as a literacy practice when reading, writing, speaking, listening, viewing, or visually representing was observed as a part of a literacy event (Bloome, Carter, Christian, Otto, \& Shuart-Faris, 2005) involving multimodal informational texts. Next, axial coding was again used for identifying specific reoccurring literacy practices that the five bilingual case studies were using. A frequency count was conducted to identify the most commonly observed literacy practice used to construct meaning with multimodal informational texts. The most frequently observed literacy practice, viewing, 
was categorized as any event in which students utilized the mode of image to construct meaning.

I returned to the transcriptions of the 233 observed Viewing transactions and completed an additional layer of analysis to identify the role of image and Viewing in meaning construction with multimodal informational texts. The final layer of analysis included an analysis of those same transactions for content knowledge and language development among the five bilingual case studies over time: image as access to meaning and content, image as prompt for discussion, image as a catalyst to seek access to written language, and image as a multimodal complement to written language.

\section{Findings}

The focus of the findings in this study is on the roles of image. However, the classroom context must be considered in order to understand the opportunities that were made available for young bilinguals to engage with texts. The inquiry-based classroom was based on the teacher's belief in the benefits of student-centered learning based on dialogic inquiry (Wells, 1999). Wells (1999) claimed that by creating a collaborative community instead of the highly structured, teacher-directed classroom, students learn with and from each other as they engage in dialogic inquiry. Haneda and Wells (2008) suggested that discourse plays an essential social role as a semiotic mediator in the construction of knowledge, and that there is a need for dialogic inquiry in the instruction of English learners.

The teacher reported basing his classroom instruction on this model of instruction. The data collection and analysis confirmed the self-reporting of the instructional approach along with additional components that were taken up during students' engagement with multimodal informational texts. The teacher provided and encouraged multiple opportunities for talk surrounding content concepts, reading and research projects. He introduced language frames for responding to viewing images ("I see....") and documenting new learning ("I learned..."). Group work and partner work was encouraged constantly as students worked on independent inquiry projects related to a broader curriculum topic.

Unlike transmission models that tend to work against central principles of language learning (Painter, 1985; Swain 1995), Gibbons (2006) reports the types of instructional scaffolds such as making meaning explicit, integrating content and language, learning through collaboration, and providing support with authentic and cognitively challenging learning tasks to be supportive for creating contexts for language learning. In the research classroom, pre-reading opportunities, background building with vocabulary support, and reading, writing and speaking strategies were introduced in minilessons to support students' independent, partner and group work on self-selected inquiry projects. The bulk of the literacy block was spent working on independent inquiry while the teacher conferred and coached individual students with reading, writing, language and strategy use. The classroom context with strategy instruction and opportunities for student-centered learning and inquiry provided opportunities for independent exploration, language learning and literacy development that included utilizing multiple roles of image. 


\section{Roles of Image}

Viewing an image to construct meaning with informational texts was the most commonly observed literacy practice in the inquiry-based classroom being recorded on 233 occasions. This might be expected with emergent bilinguals in the beginning stage of English acquisition, particularly with young students who were newly learning to decode written language. However, with deeper analysis of the videos and transcriptions, it became clear that students were not merely "looking" at images. The images assumed different roles for various purposes when constructing meaning with multimodal informational texts. The four observed roles of images included the following: image as access to meaning and content (observed 78 times); image as prompt for discussion (observed 69 times); image as a catalyst to seek access to written language (observed 46 times); image as a multimodal complement to written language (observed 40 times). There were no observed transactions with multimodal informational texts in which bilingual case studies ignored the image or it played no role in their meaning construction. In contrast, there were 18 instances when monolingual English speaking students did not attend to the image and only attended to the written language.

Image as access to meaning and content. Many students utilized images as access to meaning and content during independent reading. Students in this classroom had between 60 and 90 minutes a day for independent work that included reading and writing on their inquiry projects. However, students were allowed and encouraged to discuss and ask questions about their reading with peers and teachers. The literacy practice of using images as access to meaning and content was observed frequently with all students, but with greater frequency for the two bilinguals with the lowest scores on the English proficiency and letter identification assessments, Xochitl and Paloma. Students were observed examining multiple images in texts (single or multiple texts) without adhering to the written language. When asked to talk about what they were working on during open-ended, informal interviews, the following includes three representative samples of students' responses (pseudonyms are used for all participants):

Xochitl: "Cactus" (points at the image of the cactus).

Angel: "Looking at all the snakes. I know that one." (points to an image of a snake)

Maria: "Look, they cut all the trees (shows image and then turns a couple of pages to the next image). Look, look, there is nothing. (turns another couple of pages). These people don't have homes no more (she grabs another book next to her and turns halfway through the book to an image of a malnourished family) They don't have no food now."

None of the case study students referenced the written language during these transactions with multimodal texts. They relied solely on the image to construct meaning. When asked what she was working on during an open-ended interview, Xochitl pointed to and verbally labeled a cactus, which had been discussed during whole group 
instruction about deserts. Angel examined the image about snakes and drew on his background knowledge to make a connection to one of the snakes that he had seen before. Maria drew on multiple multimodal texts to attempt to construct an understanding of the effects of deforestation. She utilized multiple images without referencing or accessing the written language (the text was approximately at a $3^{\text {rd }}$ grade reading level) to verbally explain her understanding during an open-ended interview. The ability to analyze multiple images in multiple texts assisted in understanding and verbalizing the progression of deforestation from cutting down trees, to not having a place to live, to being malnourished.

Image as prompt for discussion. While many students engaged with texts independently, the dialogic nature of the inquiry-based classroom facilitated a great deal of student interactions about the wonderings, thoughts, reading and research. Viewing images was an accepted and valued literacy practice in this classroom. The teacher provided a language frame, "I see ___ " as a prompt to initiate dialogue about images, so students had opportunities to view an image as a class and discuss what they saw and thought. This provided a language frame to scaffold talk, vocabulary and background knowledge prior to independent inquiry. Outside of the more formalized structure of viewing and discussion, students would often use image as a discussion starter with peers.

During daily "Book Club" where students met to discuss books they enjoyed, students would often open the book to their favorite image to start the discussion about their book. Many of the students would view the image and contribute to the conversation with connections or schema about the topic. During independent reading (students had the option to work with peers or independently), students often discussed images as they looked through books together. During a videotaped observation, Maria and Paloma examined the images in an informational text about the desert and discussed them in Spanish. They first examined sequenced images of the lifecycle of a cactus and pointed to the different sequenced images as they discussed their understanding of the sequence in Spanish. They turned the page and began talking in Spanish about the picture of the snake in the sand. In this example, the images prompted a discussion in their first language to support and supplement their understanding of content they were learning as a class in English.

Images also facilitated a conversation between two students, Angel and Matt (not a bilingual case study), about the lifecycle of a frog. The following transcript reveals the progression from initial engagement, confusion, clarification and agreement. Angel showed Matt an image of a tadpole, and the following conversation ensued:

Angel: "Look at the frog in the water."

Matt: "Frogs can't live in water. They have to breathe."

Angel: "No, look." (points to the tadpole with legs in the image) 
Matt: "I don't think that is a frog. Look, it has a tail and it lives in the water. Frogs have to breathe. That is why they jump on lily pads."

Angel: "But it is a frog book." (turns to the cover of the book to show Matt the cover image)

Matt: "Let me see it." (They flip through the pages together looking at the images) "Oh, it is like a baby frog. Baby frogs can live in the water at first."

Sarah: "Yea. They're tadpoles."

Matt: "I knew that. I just forgot the name, but I knew they weren't frogs."

Angel: "Baby frogs"

Matt: "Yea baby frogs are tadpoles before they are frogs."

In this transaction, the students used image as a prompt for discussion and for learning and confirming scientific content. The discussion initially created some confusion and disagreement between the two about whether or not frogs could live underwater. Revisiting the cover image and the sequenced images of a frog's lifecycle helped to clarify an understanding of the progression from egg to tadpole to frog. Another student joined the conversation and provided the vocabulary term of tadpole to specify and clarify the confusion about a "frog" being able to live underwater. The opportunities for talk and using images facilitated a meaningful interaction that introduced and reinforced academic vocabulary and scientific concepts.

Image as a catalyst to seek access to written language. Viewing images dominated the classroom as a literacy practice used to construct meaning with multimodal informational texts. While students viewed images more than they attempted to decode written language, they often used the image as a catalyst to seek access to written language that they could not yet independently decode. They recognized the value of information in the text, and when they were particularly interested in a specific image or set of images and wanted more information than the image alone provided, they would seek assistance from a peer or teacher who could read the written language to them.

Maria, who was so interested in the images of deforestation in the rainforest, placed sticky notes by her favorite images and asked the teacher to read the captions of those pictures. When he read the captions, she told him she wanted to research deforestation and asked if he would help her write the information down. He reread her the caption and asked her what she wanted him to write. He then scribed her summary of the caption on a sticky note and asked her to create an illustration so that she could remember it when she was sharing it with the group. They did this for three separate images. The teacher's reading the written language, asking for her to verbalize what she wanted him to write, scribing her learning, and encouraging an illustration provided 
multiple scaffolds for Maria to learn, document her understanding, and facilitate a successful verbal sharing with peers during group share.

During another interaction, Julio invited Angel and Paloma to "Come see this book I got." He had a small reptile reference book. He flipped to his favorite photograph of a boa constrictor. He turned to the next page and said, "See. It squeezes it so hard it dies. It can't breathe. It doesn't even have to chew." He pointed to the picture of a boa with a large visible lump after having swallowed its prey. Angel told Julio and Paloma that he saw a rattlesnake like the image and his dad ran over it with their truck. Julio immediately corrected him and told him the picture was of a boa constrictor, not a rattlesnake. Angel argued that his dad told him it was a rattlesnake. Julio asked Allison (a monolingual English-speaking student who could decode fluently) to read the name of the snake. Then, he brought her over to Paloma and Angel and said, "Allison says it is a boa constrictor. Right, Allison?" Allison confirmed Julio's knowledge of the boa constrictor by providing access to the written language for Angel, Julio and Paloma.

Image as a multimodal complement to written language. The final observed role of image in this study was as a multimodal complement to written language. The sophisticated interplay of written language and image in multimodal informational texts facilitated meaning construction for young bilinguals. In these observed transactions, students relied on both written language that they were able to decode and images in order to develop a deeper understanding of the content. The experiences ranged from reading labels and captions to decoding multiple sentences in a short paragraph.

Labels and captions were explicitly taught as important non-fiction text features. Students were asked by the teacher to utilize labels and captions on their informational illustrations, so they knew the value of these two text features. Because of the authentic use of text features in their own writing and reading, these students' understanding of text features served a purpose greater than simply demonstrating their ability to reproduce a text feature for their teacher. Paloma began an inquiry project on plants and quickly became fascinated with the Venus flytrap. When asked to talk about what she was working on, she began by referencing the image. Then, she read the caption and labels aloud to provide additional information.

Paloma: "The Venus flytrap. It eats bugs." (points to the picture of a cricket getting close to the leaves)

Paloma: (reading slowly with finger under each word) "A cricket crawls toward the leaves that can shut tight."

Paloma then pointed to the different labeled parts of the Venus flytrap and read them aloud. By this time in the year, she was able to use her emerging decoding skills to utilize the modes of image and written language to comprehend and represent her new understanding about the Venus flytrap.

Another example of this role of image was observed when Julio, Angel and Matt were browsing an informational text with the word birds in the title. They were discussing the images, and they came to a page with bats. The following transcription 
describes their discussion about the content of the images leading up to reading multiple sentences in a short paragraph.

Julio: "What? Bats aren’t birds!"

Angel: "Si. Este es un libro sobre pájaros." (Yes, this is a book about birds)

Matt: "What did you say?"

Angel: "This is a bird book."

Matt: "Oh. Well, I guess they can fly."

Julio: "No. They are not birds. I know."

(Julio reads two captions aloud- they are about the type of bat that is in the images)

Julio, Angel and Matt started reading together and helping each other sound out the words in the body of the paragraph. They found out that many people think bats are birds, but they are actually mammals. They have fur and are born alive from their mother, not hatched from an egg. Julio commented, "Then why is it in the bird book?" This transaction with image and written language exemplified the importance of the interplay between both modes.

\section{Support for Content Knowledge and Language Development}

The transactions where viewing an image assisted in the meaning construction of multimodal informational texts were initially analyzed for the role of the image. Then, the same transactions were revisited and analyzed for ways the image was a support for content knowledge and language development for the young bilingual case studies. Image supported content knowledge and language development in the following ways: builds on background knowledge of world around them by providing comprehensible input; emphasizes vocabulary; and facilitates discussion.

Children, regardless of their home language, have knowledge and curiosities about the world around them. Images in the informational texts allowed students to make connections to the language by viewing an image or sequence of images. For example, the students were familiar with frogs, but were able to gain a deeper understanding of the frog's lifecycle by viewing the sequence of images. The image made the content comprehensible. This transaction not only built content understanding, but it also provided an opportunity for discussion and vocabulary building as they learned (or remembered) the term tadpole.

Images provide a foundation for young bilinguals to build vocabulary. For some students, it began with a language frame ("I see __") to structure dialogue and label what they were seeing in the image. Many students were originally exposed to new English vocabulary when another student used the vocabulary in English when viewing the image. Multiple and repeated exposure to vocabulary in context assisted students in 
acquiring and being able to use that vocabulary in future conversations or writing. New content-specific academic vocabulary such as tadpole, mammal, and deforestation was initially acquired largely because of access to the mode of image.

One of the most significant benefits of image as a support for content and language development was the opportunity it provided for discussion. Emerging bilinguals initially relied heavily on the language frame "I see" to participate in discussions. However, their repeated exposure to language in context about the images assisted vocabulary acquisition. Discussion surrounding the images ranged from personal connections to content disagreements to working together to decode the accompanying written language. These discussions provided exposure to and opportunities to practice both social and academic language in authentic, low-anxiety situations.

\section{Discussion}

All young students, regardless of first language, utilize images for various purposes during transactions with texts. In this study, the focus was on the roles of images for young bilinguals. There were no observed instances of young bilinguals not adhering to the image, whereas there were 18 documented instances of this with monolingual English speakers. This discrepancy leads to additional questions about similarities and differences between the roles of image for bilinguals and monolinguals. However, this study is not a cross-case analysis of monolingual and bilingual students, but rather, an in-depth examination of bilinguals' use of images in multimodal informational text to contribution to meaning making, discussion and language development.

Building on the work of scholars who examine ways children engage with text (e.g., Hassett \& Schieble, 2007; Serafini, 2012), this research explores the affordances and roles images in informational text played for young bilinguals. As Painter, Martin, and Unsworth (2013) note, the knowledge among literacy educators about visual images is lacking when compared to the mode of written text. Mohan (1986) identified key visuals that lend themselves to knowledge structures across the curriculum, and Early (1990) identified these as having three major applications: generative, explanatory, and evaluative. Drawing on this initial understanding of key visuals, this study takes a yearlong ethnographic approach to examine the four specific roles that images played for young bilinguals when engaging with informational text in an inquiry-based setting. Understanding the roles of image over the course of a year, as described in this study, adds to the current body of research by providing implications for possible instructional considerations for scaffolding meaning-making among bilinguals engaging with multimodal informational text.

\section{Why They Used Image}

The purpose of this study was to examine how young bilinguals construct meaning with multimodal informational texts. Once it was discovered that the most frequently used literacy practice to do that included viewing an image, the role of image was analyzed. The role of image played four distinct, but important roles: image as access to meaning and content; image as prompt for discussion; image as a catalyst to seek access to written language; image as a multimodal complement to written language. The 
four observed roles of images contributed to knowledge construction and second language development. These findings add to the understanding that multimodal informational texts provide affordances for meaningful language and learning opportunities for students who speak more than one language.

The young bilinguals utilized multiple modes, with an emphasis on image, to gain content knowledge while simultaneously acquiring literacy skills and both social and academic vocabulary. Multimodal informational texts provided access to background knowledge for students who were not yet fluent in English or decoding written language. The image allowed them to utilize their knowledge about the world around them in order to acquire new vocabulary in context. With the understanding of new and complex texts that students encounter and ways in which young bilinguals rely on multiple modes, the importance for instructional attention is clear. Educators can support content and language development through an instructional focus on multimodal informational texts, image and visual literacy skills.

\section{Limitations}

There are multiple limitations of this study. The first limitation is the small sample size of one classroom, and specifically, five case studies. Additionally, the validity of interviewing young children and linguistically marginalized populations can be problematic. Finally, the nature of an inquiry-based, student-centered classroom is not replicable in terms of fidelity analysis and future instructional implementation/replication. Because of this, the findings are not generalizable.

\section{Future Research}

There are multiple possibilities for future research, particularly cross-case analysis studies. A cross-case analysis of the monolingual and bilingual students' use of images for meaning construction could provide deeper insight into the differences needed for instruction and scaffolding. Another cross-case analysis study could include the analysis of the roles of image in multimodal informational text in an inquiry-based classroom as compared to a transmission model setting. This could provide findings related to the impact the classroom environment and instruction played on the way young learners took up the roles of image to contribute to meaning construction and language development.

\section{Implications}

The implications for instruction include developing an understanding of the affordances provided by images in informational texts. Teachers can identify and draw attention to "reading the visual" and the multimodality of informational texts. This attention to image, and instruction to support attention to image, provides an opportunity to expand on students' understanding and language development. In addition to valuing the image and teaching students to value the image, English learners would benefit from teachers explicitly sharing the roles of image as they are presented in new learning experiences. Through authentic transactions with informational texts and images, young bilinguals will gain access to meaning and content, participate in meaningful discussions, seek access to written language, and understand that image is a multimodal complement to written language. 


\section{References}

Anstey, M., \& Bull, G. (2006). Teaching and learning multiliteracies: Changing times, changing literacies. Newark, DE: International Reading Association.

Arizpe, E., \& Styles, M. (2003). Children reading pictures: Interpreting visual texts. With contributions from H. Bromley, K. Coulthard \& K. Rabey. London and New York: Routledge Falmer.

Bloome, D., Carter, S. P., Christian, B. M., Otto, S., \& Shuart-Faris, N. (2005). Discourse analysis and the study of classroom language and literacy events: A microethnographic perspective. Mahwah, NJ: Lawrence Erlbaum Associates.

Bradley, L., \& Bryant, P. E. (1983). Categorizing sounds and learning to read: A causal connection. Nature, 303, 419-421.

Caswell, L., \& Duke, N. K. (1998). Non-narrative as a catalyst for literacy development. Language Arts, 75, 108-117.

Chall, J. S. (1983). Stages of reading development. New York: McGraw Hill.

Clay, M. M. (1982). Observing young readers: Selected papers. Portsmouth NH: Heinemann.

Clay, M. M. (2000). Concepts about print: What are children learning about the way we print language? Portsmouth, NH: Heinemann.

Creswell, J. (2002). Educational research: Planning, conducting, and evaluating quantitative and qualitative research. Upper Saddle River, NJ: Pearson Education.

Creswell, J. W. (2007). Educational research. Upper Saddle River, NJ: Prentice Hall.

Crotty, M. (1998). The foundations of social research: Meaning and perspective in the research process. London: Sage.

Cummins, J., Mirza, R., \& Stille, S. (2012). English language learners in Canadian Schools: Emerging directions for school-based policies. TESOL Canada Journal, 29(6), 25-48.

Duke, N. K. (2000). 3.6 minutes per day: The scarcity of informational texts in first grade. Reading Research Quarterly, 35(2), 202-224.

Dyson, A. H. (2013). Relations Between Oral Language and Literacy. The Encyclopedia of Applied Linguistics. DOI: 10.1002/9781405198431.wbeal1002

Early, M. (1990). ESL beginning literacy: A content-based approach. TESL Canada Journal 7(2), 82-93.

Echevarria, J., Short, D., \& Vogt, M. E. (2008). Making content comprehensible for English learners: The SIOP Model. Boston, MA: Pearson Education.

Einarsdottir, J., \& Wagner, J. T. (2006). Nordic childhoods and early education: Philosophy, research, policy, and practice in Denmark, Finland, Iceland, Norway, and Sweden. Greenwich, CT: Information Age Publishing Inc.

Gallas, K. (1994). The languages of learning. How children talk, write, dance, draw, and sing their understanding. New York: Teachers College Press.

Geertz, C. (1973). Thick description: Toward an interpretive theory of culture. In C. Geertz (Ed.), The interpretation of cultures: Selected essays (pp. 3-32). New York: Basic Books. 
Gibbons, P. (2002). Scaffolding language, scaffolding learning: Teaching second language learners in the mainstream classroom. Portsmouth, NH: Heinemann.

Guba, E.G., \& Lincoln, Y. S. (1981). Effective evaluation: Improving the usefulness of evaluation results through responsive and naturalistic approaches. San Francisco, CA: Jossey-Bass.

Guccione, L. M. (2011). Integrating literacy and inquiry for English learners. The Reading Teacher, 64(8), pp. 567-577.

Haneda, M., \& Wells, G. (2008). Learning an additional language through dialogic inquiry. Language and Education, 22(2), 114-136.

Hassett, D. D., \& Schieble, M. B. (2007). Finding space and time for the visual in K-12 literacy instruction. English Journal, 97(1), 62-68.

Herrera, S. G., Perez, D. R., \& Escamilla, K. (2010). Teaching reading to English language learners: Differentiated literacies. Boston: Allyn \& Bacon.

Hulme, C., Muter, V., Snowling, M., \& Stevenson, J. (2004). Phonemes, rimes, vocabulary, and grammatical skills as foundations of early reading development: Evidence from a longitudinal study. Developmental Psychology, 40, 665-681.

Jeong, J., Gaffney, J., \& Choi, H. (2010). Availability and use of informational texts in second, third and fourth-grade classrooms. Research in the Teaching of English, 44(4), 435-456.

Kilbride, K. M., \& D’Arcangelo, L. (2002). Meeting immigrant community college students' needs on one Greater Toronto area college campus. Canadian Journal of Higher Education 32(2), 1-26.

Kress, G. (1997). Before writing: Rethinking the paths to literacy. New York: Routledge.

Kress, G. (2003). Literacy in the new media age. London: Routledge.

Kress, G. (2010). Multimodality: A social semiotic approach to contemporary communication. New York: Routledge.

Kress, G., \& Van Leeuwen, T. (2006). Reading images. The grammar of visual design. New York: Routledge.

Kvale, S. (1996). Interviews: An introduction to qualitative research interviewing. Thousand Oaks, CA: Sage.

Lemke, J. L. (1998). Multiplying meaning: Visual and verbal semiotics in scientific text. In J. R. Martin \& R. Veel (Eds.), Reading science: Critical and functional perspectives on discourses of science (pp. 87-113). London: Routledge.

Maloch, B., \& Zapata, A. (2012). The social and textual practices of third graders with informational texts. In P.J. Dunston, S.K. Fullerton, C.C. Bater, K. Headley \& P.M. Stecker (Eds.), $61^{\text {st }}$ Yearbook of the Literacy Research Association (pp. 410420), Oak Creek, Wisconsin: Literacy Research Association.

Merriam, S. B. (1998). Qualitative research and case study applications in education. San Francisco, CA: Jossey-Bass.

Mohan, B. A. (1986). Language and Content. Reading, MA: Addison-Wesley.

Moses, L. (2013). Viewing as a cultural tool in the construction of meaning with expository texts for young bilinguals. Journal of Language and Literacy Education 9(2), 72-93.

Narey, M. (Ed.). (2009). Learning through arts-based early childhood education. New 
York: Springer Publishing Company.

National Assessment of Educational Progress. (2009). The nation's report card:

Reading grade 4 national results. Washington, DC: Author.

National Center for Education Statistics (2011). The Nation's Report Card: Reading 2011(NCES 2012-457). Institute of Education Statistics, U. S. Department of Education, Washington, D.C.

National Research Council. (1997). Improving schooling for language-minority children. Washington DC: National Academies Press.

Office of English Language Acquisition, Language Enhancement and Academic Achievement for Limited English Proficient Students. (2010). The growing number of English learner students 1997/1998-2007/2008. Washington, DC: U.S. Department of Education.

Painter, C. (1985). Into the mother tongue. Geelong, Victoria: Deakin University Press.

Painter, C., Martin, J.R., \& Unsworth, L. (2013). Reading visual narratives: Image analysis of children's picture books. Bristol, CT: Equinox Publishing.

Pappas, C. (1991). Fostering full access to literacy by including information books. Language Arts, 68, 449-462.

Purcell-Gates, V., Duke, N.K., \& Martineau, J.A. (2007). Learning to read and write genre specific text: Roles of authentic experience and explicit teaching. Reading Research Quarterly, 42, 8-45.

Serafini, F. (2010). Reading multimodal texts: perceptual, structural and ideological perspectives. Children's Literature in Education. 22, 70-89.

Serafini, F. (2012). Expanding the four resources model: reading visual and multi-modal texts. Pedagogies: An International Journal, 7(2), 150-164.

Serafini, F. (2014). Reading the Visual: An Introduction to Teaching Multimodal Literacy. New York: Teachers College Press.

Sipe, L. (1998). How picture books work: a semiotically framed theory of text-picture relationships. Children's Literature in Education 29(2), 97-108.

Strauss, A. L. (1987). Qualitative analysis for social scientists. Cambridge: Cambridge University Press.

Swain, M. (1995). Three functions of output in second language learning. In G. Cook \& B. Seidlehofer (Eds.), Principle and practice in applied linguistics: Studies in honour of H. G. Widdowson (pp. 125-144). Oxford, UK: Oxford University Press.

The New London Group. (1996). A pedagogy of multiliteracies: Designing social futures. Harvard Educational Review, 66, 60-92.

Unsworth, L., \& Wheeler, J. (2002). Re-valuing the role of images in reviewing picture books. Reading: Language and Literacy 36(2), 68-74.

Watkins, J. K., Miller, E., \& Brubaker, D. (2004). What are students really learning from pictoral representations? Journal of Visual Literacy, 24(1), 23-40.

Wells, G. (1999). Dialogic inquiry: Towards a sociocultural practice and theory of education. Cambridge, United Kingdom: Cambridge University Press.

Yatvin, J. (2007). English-only teacher in mixed-language classrooms: A survival guide. Portsmouth, NH: Heinemann. 


\section{Author Biography}

Dr. Lindsey Moses is an Assistant Professor of Literacy at Arizona State University in the Mary Lou Fulton Teachers College. Lindsey's research interests involve using sociocultural perspectives to explore how young learners construct meaning in various instructional settings. 